\title{
Fast-Transient PCCM Switching Converter With Freewheel Switching Control
}

\author{
Dongsheng Ma, Senior Member, IEEE, and Wing-Hung Ki, Member, IEEE
}

\begin{abstract}
This brief presents a new switching converter operating in pseudo-continuous-conduction mode (PCCM) with freewheel switching control. Compared with conventional discontinuous-conduction mode (DCM) converters, this converter demonstrates much improved current handling capability with reduced current and voltage ripples. The control-to-output transfer function exhibits a single-pole behavior, making the load transient response much faster than its $\mathrm{CCM}$ counterparts. Simulation and experimental results show that, with a 6-V, 6-W load and a 10-V unregulated supply, the PCCM converter has a current ripple of only $1.1 \mathrm{~A}$ and a ripple voltage of only $58 \mathrm{mV}$, while a DCM converter has a current ripple of $2.2 \mathrm{~A}$ and a ripple voltage of $220 \mathrm{mV}$. In addition, the PCCM converter takes only $25 \mu$ s to respond to a 500-mA load current change while a CCM one requires $1.4 \mathrm{~ms}$.
\end{abstract}

Index Terms-Current ripple, freewheel switching, pseudo-continuous-conduction mode (PCCM), switching converter, transient response, voltage ripple.

\section{INTRODUCTION}

D EVELOPMENT of high-performance electronic devices imposes new challenges on power supplies. With the supply voltage reduceing from 5 to $3.3,2.5$, and even $0.8 \mathrm{~V}$ in the future, the current level in state-of-the-art computer CPUs increases from a few amperes to 30-50 A for faster computation and more powerful functions [1]. These large numbers of computing activities lead to drastic current changes in a short time in the power supplies. To maintain high regulation performance and to ensure system stability, the power supplies must have the capability of handling large output current with fast transient response [2].

Switch mode power converters, or switching converters in short, have been widely. It is an essential component to provide clean and quality power for low-voltage electronic devices. Fig. 1 shows the circuit block diagram of a conventional buck switching converter. It provides electronic devices with regulated supply voltage, high efficiency and flexible voltage conversion. Compared to boost and flyback topologies, the buck converter enjoys a continuous output current when operating in continuous-conduction mode (CCM), leading to smaller current ripple and thus lower switching noise. In addition, CCM operation is much more favorable for large current applications, because it can deliver more current than the converter operating in discontinuous-conduction mode (DCM) [3]. However, a DCM converter usually has a much faster transient response and a loop gain that is easier to compensate than a CCM converter. With the

Manuscript received November 29, 2006; revised March 9, 2007. This paper was recommended by Associate Editor E. Alarcon.

D. Ma is with the Department of Electrical and Computer Engineering, the University of Arizona, Tucson, AZ 85721 USA (e-mail: ma@ece.arizona.edu).

W.-H. Ki is with the Department of Electronic and Computer Engineering, the Hong Kong University of Science and Technology, Hong Kong.

Digital Object Identifier 10.1109/TCSII.2007.900903

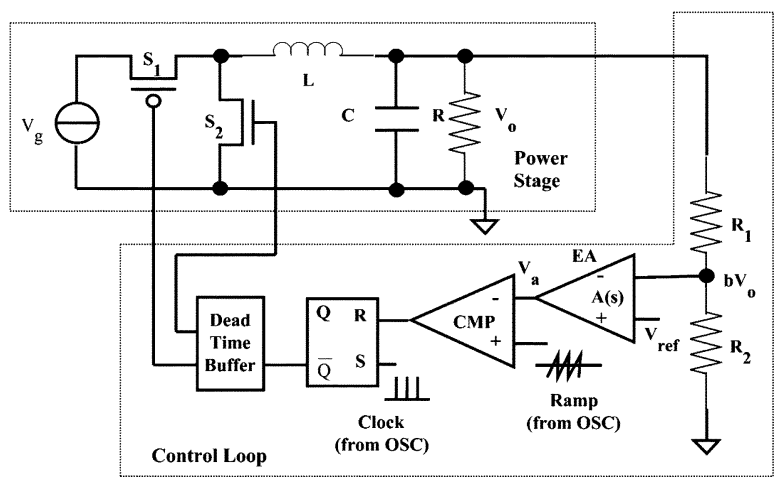

Fig. 1. Conventional buck switching converter.

great demands on both fast transient response and large current capability, it would be very desirable to have a new converter incorporating advantages of both CCM and DCM converters.

To solve the mentioned issues, we present in this brief a converter that operates in a new operation mode - the pseudo CCM (PCCM), made possible by freewheel switching control. The rest of the brief is organized as follows. In Section II, we review state-of-the-art switching converter designs, and then discuss their drawbacks for high-current fast-transient applications. In Section III, we introduce our design with detailed circuit structure, operation scheme and topology extensions. Simulation and experimental results are provided in Section IV. Finally, we conclude our research efforts in Section V.

\section{Review of Prior ARTS \& Design Motivation}

\section{A. Current Ripple and Switching Noise at Heavy Load}

The operation of a switching converter can be classified as either CCM or DCM, according to its inductor current, as shown in Fig. 2. When the load current is heavy ( $R$ in Fig. 1 is small), the inductor current stays above zero to supply more current to the output. The converter thus operates in CCM [Fig. 2(a)], and each switching period $T_{s}$ is divided into two parts: $D_{1} T_{s}$ and $D_{2} T_{s}\left(D_{1}+D_{2}=1\right)$. It ramps down during $D_{2} T_{s}$ when $S_{1}$ is off and $S_{2}$ is on. When the load is light ( $R$ in Fig. 1 is large), the inductor current ramps up, then down to and stays at zero every cycle. Each switching cycle is divided into three parts: $D_{1} T_{s}$, $D_{2} T_{s}$ and $D_{3} T_{s}\left(D_{1}+D_{2}+D_{3}=1\right)$. The inductor current waveform in $D_{1} T_{s}$ and $D_{2} T_{s}$ is similar to that in CCM, but stays at zero during $D_{3} T_{s}$ when $S_{1}$ and $S_{2}$ are off. The converter then operates in DCM [Fig. 2(b)]. For a CCM converter, the dc level of the inductor current $I_{O}$ is increased to supply a larger load current, while the current ripple $\Delta I$ is kept constant and small. Hence, the output ripple voltage and switching noise are relatively small. However, for a DCM converter, to supply the same load current, a smaller value of inductor has to be used, and the inductor current increases more sharply from zero to a 
(a)

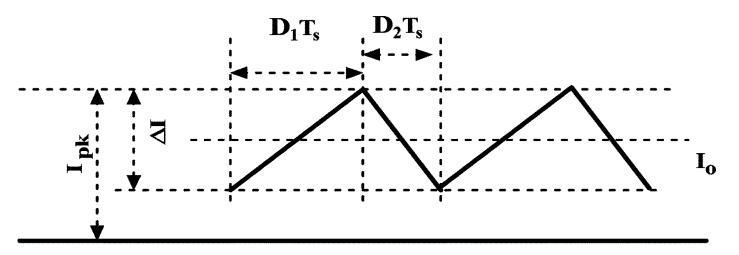

(b)

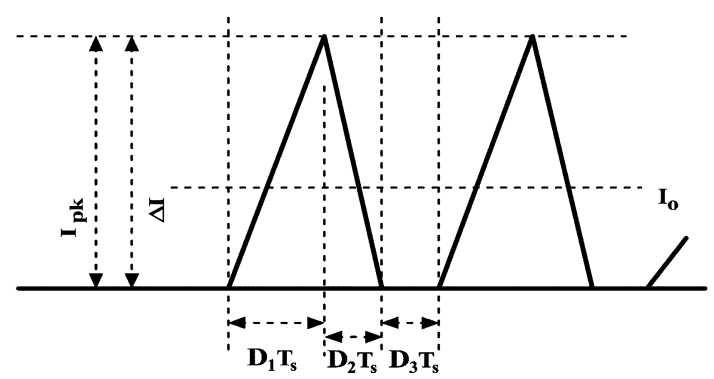

Fig. 2. Inductor current of a switching converter in (a) CCM and (b) DCM.

much higher peak current $I_{\mathrm{pk}}$ [Fig. 2(b)]. As a result, the current ripple $\Delta I$ is very large, generating large switching noise and ripple voltages at the output.

\section{B. Transient Response and Loop Gain Bandwidth}

A switching converter may operate with either voltage- or current-programming control. With a voltage-programming control, the loop gain transfer function can be shown to be [4]

$$
T(s)=A(s) \cdot H(s)=\frac{A(s) b \cdot V_{O}}{D V_{m}} \frac{1}{1+\frac{1}{Q} \frac{s}{\omega_{0}}+\left(\frac{s}{\omega_{0}}\right)^{2}}
$$

where $A(s)$ is the gain of the error amplifier that consists of an op-amp and a compensation network, $H(s)$ is the control-tooutput transfer function, $b$ is the scaling factor, $D$ is the duty ratio of the converter, $V_{m}$ is the peak-to-peak voltage of the oscillator ramp, $V_{O}$ is the output voltage, $\omega_{O}=1 / \sqrt{L C}$ is the frequency of the complex poles, and $Q$ is the quality factor. As shown in Fig. 3(a), the existence of the complex poles in the control-to-output transfer function makes it very difficult to design a compensator to achieve a loop gain with large bandwidth [4]. When the converter operates in current-programming control, the control-to-output transfer function consists of two separated real poles [4]. Pole-zero compensation methods can then be used to achieve a larger loop-gain bandwidth [5]. However, a current sensing circuit is needed for loop control and special ramp compensation technique is needed to avoid sub-harmonic oscillation [6]. As a result, the operation of the converter is very sensitive to the current sensing signal that is seriously corrupted by switching noise. The corresponding circuit design complexity would be high as well. Hence, our research efforts are put on voltage-programming converters in this brief.

As discussed in Section II-A, although DCM operation is not preferred for heavy load current applications, it exhibits a very attractive feature on the transient response. This can be explained by its loop gain transfer function [7]

$$
\begin{aligned}
T(s) & =A(s) \cdot H(s) \\
& =\frac{A(s) b}{V_{m}}\left(\frac{2 V_{O}(1-M)^{3 / 2}}{(2-M) \sqrt{K} M}\right) \frac{1}{1+s R C \frac{1-M}{2-M}}
\end{aligned}
$$

where $M\left(=V_{o} / V_{g}\right)$ is the voltage conversion ratio, $\mathrm{R}$ is the equivalent load resistance, $K=2 L / R T_{s}$ and $T_{s}$ is the

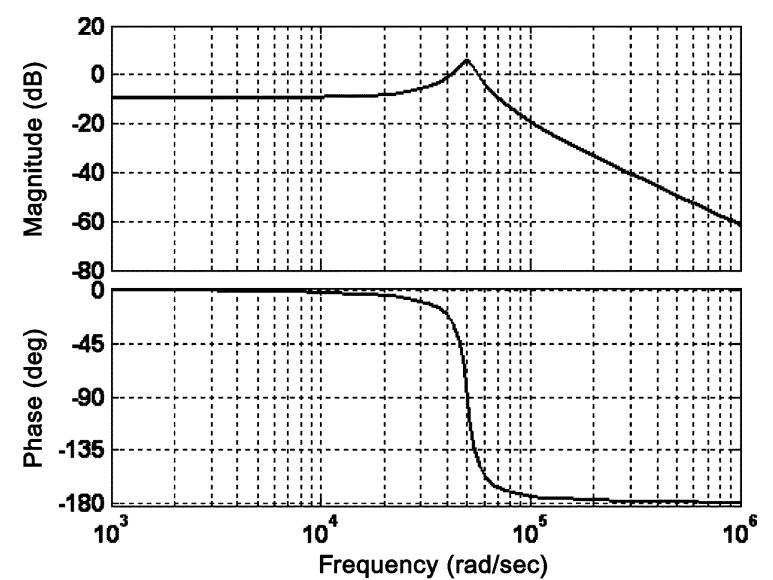

(a)

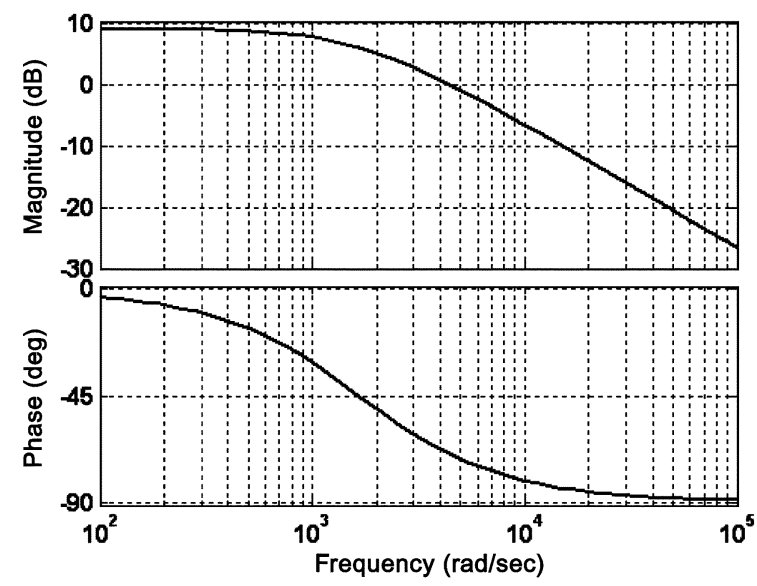

(b)

Fig. 3. Bode plots of the control-to-output transfer function, when a buck converter operates in (a) CCM, and (b) DCM.

switching period. For the control-to-output transfer function of a DCM buck converter, there is only one pole in the low frequency range as shown in Fig. 3(b) [8], and the converter can be stabilized by pole-zero compensation, giving a much broader bandwidth than the CCM converter [9].

\section{PROPOSED PCCM CONVERTER}

\section{A. Proposed Converter With Freewheel Switching Control}

To effectively reduce the peak inductor current in single-inductor multiple-output (SIMO) switching converters, we proposed a freewheel switching control scheme [10]. Due to the nature of time-multiplexing control between the sub-converters, the transient performance was not much improved. However, if the technique is applied to traditional single-output converters, both current handling capability and transient response can be significantly enhanced.

A new switching converter is thus proposed in Fig. 4(a). The operation can be explained with reference to Fig. 4(b). Different from conventional buck converters, an additional pMOS power switch $S_{3}$ (named a freewheel switch) is added across the inductor. During $D_{1} T_{s}$, the pMOS power switch $S_{1}$ is turned on, while the switches $S_{2}$ and $S_{3}$ are both off. The inductor current increases with a slope of $\left(V_{g}-V_{o}\right) / L$. In $D_{2} T_{s}, S_{1}$ and $S_{3}$ are turned off. The nMOS power switches $S_{2}$ is turned on. The inductor current decreases with a slope of $-V_{o} / L$ until it hits a current level of $I_{d c}$. Then the converter enters the period of 


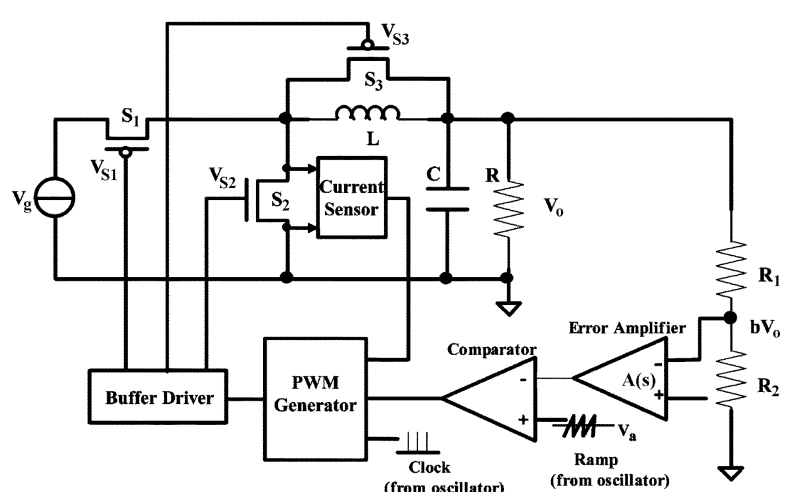

(a)

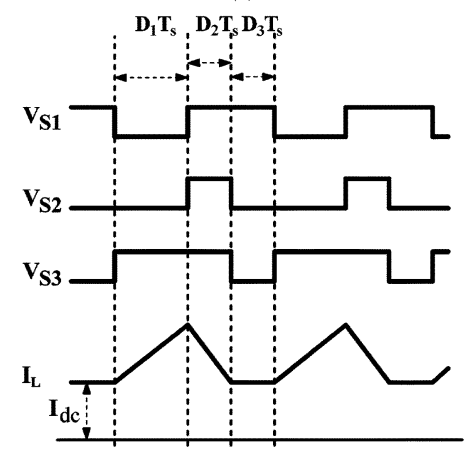

(b)

Fig. 4. (a) Block diagram of the proposed converter. (b) Timing diagram of the proposed converter.

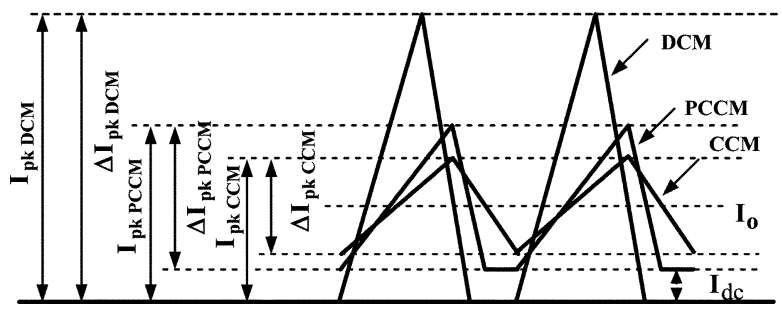

Fig. 5. Inductor current waveforms in three different operation modes.

$D_{3} T_{s}$ where $S_{3}$ is turned on while both $S_{1}$ and $S_{2}$ are turned off. The inductor current stays constant at $I_{\mathrm{dc}}$ because the switch $S_{3}$ shorts the inductor $\mathrm{L}$ and the voltage across the inductor is thus equal to zero. The operation of freewheel switching buck converter is similar to a traditional DCM one, but the inductor current stays at a constant value of $I_{\mathrm{dc}}$ instead of zero during $D_{3} T_{s}$. This allows the converter to deliver larger current by simply boosting the current level of $I_{\mathrm{dc}}$ in Fig. 5 .

The level of $I_{\mathrm{dc}}$ is adaptively determined by the real-time load power of the converter. Since $V_{o}$ is fixed, the load power is linearly proportional to the load current and the inductor current. A compact current sensing circuit is thus implemented for online current measurement [11]. Based on the load current, one of the eight predefined levels of $I_{\mathrm{dc}}$ will be used. If the current sensing circuit senses a higher current, a higher level of $I_{\mathrm{dc}}$ is chosen. Otherwise, a lower one would be used for a low power load. The control circuit makes sure that $I_{\mathrm{dc}}$ is always slightly lower than the average load current $I_{O}$ (Fig. 5) to ensure PCCM operation, and adjusts $I_{\mathrm{dc}}$ accordingly to limit the turn-on time of $S_{3}$ to be less than $5 \%$ of each switching period. Hence, the average current of $S_{3}$ is much less than that of $S_{1}$ and $S_{2}$, and the power

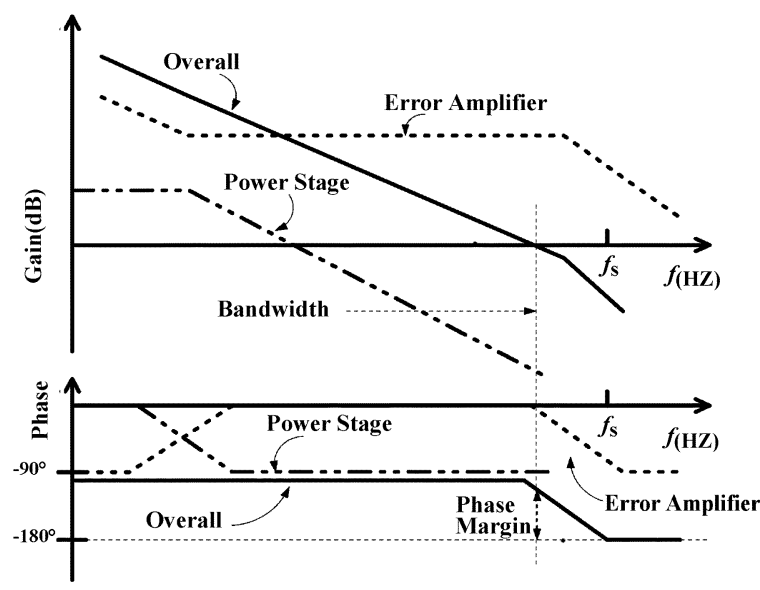

(a)

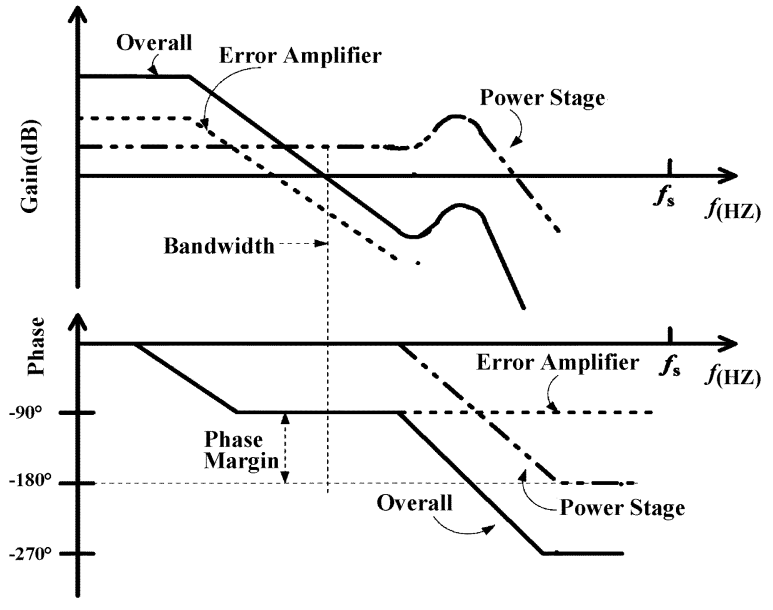

(b)

Fig. 6. (a) Pole-zero compensation for PCCM buck converter. (b) Dominantpole compensation for CCM buck converter.

loss due to $S_{3}$ can be very low, allowing $S_{3}$ to be implemented by a much smaller power transistor. This operation mode was named the PCCM in [10], because it achieves a similar current handling ability as a CCM converter, but the inductor waveform resembles a DCM converter. The advantages of the converter are reduced current and voltage ripples.

\section{B. Bandwidth Enhancement on the Proposed Design}

Another feature of PCCM operation is a better transient performance. Similar to the DCM converter, the PCCM converter exhibits a single-pole system behavior. This can be explained with reference to Fig. 2(b). For a CCM converter, the power stage is a second-order system due to the two reactive components $C$ and $L$ with corresponding state variables the capacitor voltage $V_{c}$ and the inductor current $I_{L}$. However, for a DCM converter, $I_{L}$ is reset to zero every switching cycle, eliminating $I_{L}$ as a state variable and the order of the system is reduced to 1 . For the PCCM case, $I_{L}$ is reset to a constant $I_{\mathrm{dc}}$ every switching cycle. In terms of small-signal analysis, $I_{L}$ is equivalent to reset to zero, and the transfer function of the power stage is then first order. Therefore, pole-zero compensation [9] can be use to broaden the loop-gain bandwidth, as shown in Fig. 6(a). For comparison, the dominant pole compensation method for a CCM converter is demonstrated in Fig. 6(b). 


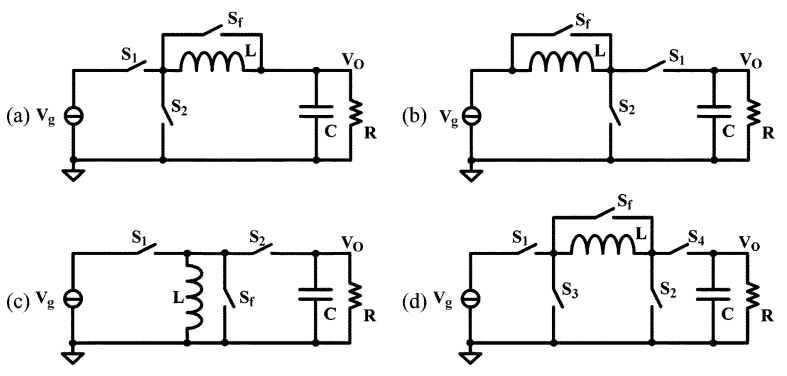

Fig. 7. PCCM converters with freewheel switch in (a) buck, (b) boost, (c) flyback, and (d) non-inverting flyback topologies, respectively.

TABLE I

DESIGN SPECIFICATIONS OF THE THREE CONVERTERS

\begin{tabular}{cccc}
\hline & DCM & CCM & PCCM \\
\hline Filter capacitor $\mathrm{C}(\mu \mathrm{F})$ & 50 & 20 & 20 \\
Inductor $\mathrm{L}(\mu \mathrm{H})$ & 10 & 20 & 20 \\
Load $\mathrm{R}(\Omega)$ & 6 & 6 & 6 \\
Switching frequency $f_{\mathrm{s}}(\mathrm{kHz})$ & 100 & 100 & 100 \\
Input voltage $\mathrm{V}_{\mathrm{g}}(\mathrm{V})$ & 10 & 10 & 10 \\
Output voltage $\mathrm{V}_{\mathrm{O}}(\mathrm{V})$ & 6 & 6 & 6 \\
Voltage reference $\mathrm{V}_{\text {ref }}(\mathrm{V})$ & 2 & 2 & 2 \\
Scaling factor b & $1 / 3$ & $1 / 3$ & $1 / 3$ \\
\hline
\end{tabular}
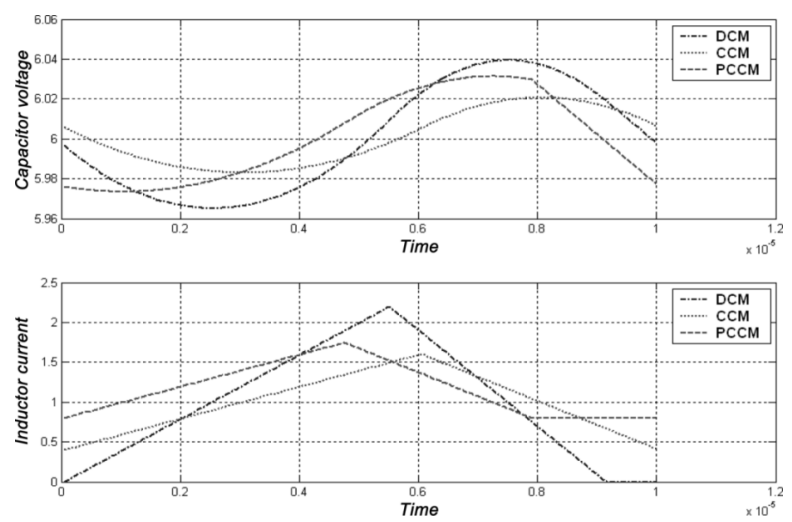

Fig. 8. Output voltages and inductor currents of the three converters.

\section{Topology Extensions}

The addition of the freewheel switch $S_{f}$ across the inductor for PCCM operation could be extended to other converter topologies, as shown in Fig. 7.

\section{Simulation AND EXPERIMENTAL Results}

To verify the design ideas, three buck converters, operating in DCM, CCM, and PCCM, respectively, are designed. The key design specifications are listed in Table I. For fair comparison, the converters operate with the same power load, switching frequency and input and output voltages. However, to deliver the same power, the change in the inductor current of the DCM converter has to be much larger than the others, and a smaller inductor $(10 \mu \mathrm{H})$ has to be used. Consequently, to keep a similar ripple voltage, the DCM converter needs a larger filtering capacitor $(50 \mu \mathrm{F})$. Despise a larger capacitor, the DCM converter still resulted in the largest current and voltage ripples (Fig. 8) and it also causes a sluggish transient response. Hence, the DCM converter gives the worst transient response and current and voltage ripples. The rest of the comparisons are thus focused on the CCM and PCCM converters.

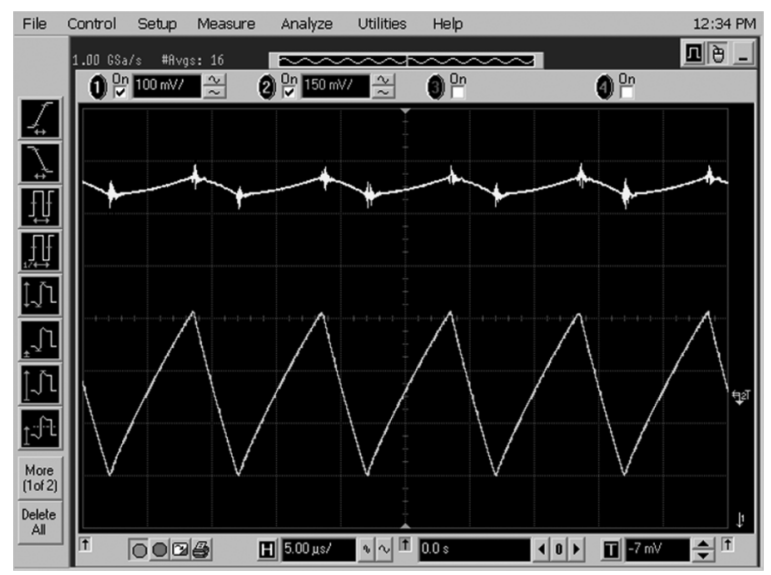

Fig. 9. Output voltage and inductor current of CCM converter.

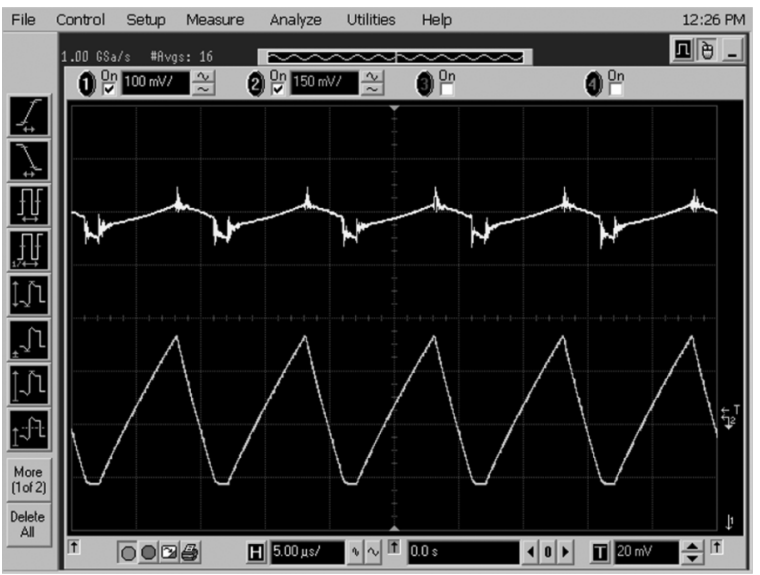

Fig. 10. Output voltage and inductor current of PCCM converter.

Figs. 9 and 10 show the measured output voltage and inductor current of the CCM and PCCM converters, respectively. For the CCM converter, the peak-to-peak ripple voltage is $48 \mathrm{mV}$ with $52-\mathrm{mV}$ glitches, and the measured current ripple is $1.2 \mathrm{~A}$. For the PCCM converter, the peak-to-peak ripple voltage is $58 \mathrm{mV}$, with $41-\mathrm{mV}$ glitches, and the measured current ripple is $1.1 \mathrm{~A}$. Hence, with the same load power of $6 \mathrm{~W}$, the PCCM converter has similar current handling capability as the CCM converter without compromising voltage and current ripples. To evaluate the transient performance, we first examine the compensation methods used by the converters. As discussed in Section II-B, the CCM converter has a pair of complex poles. To guarantee a stable operation, dominant pole compensation is used to reduce the gain below $0 \mathrm{~dB}$ before reaching the resonance frequency of the complex poles. With the parameters in Table I, the loop gain unity gain bandwidth is designed to be $700 \mathrm{~Hz}$, as shown in Fig. 11. Even with a low bandwidth, the gain margin is only $9 \mathrm{~dB}$ at the complex-pole frequency of $8 \mathrm{kHz}$. Dominant compensation can also be used for the PCCM converter. However, since there is only one low-frequency pole in the control-to-output transfer function, pole-zero compensation could be used to extend the bandwidth [8]. The introduced zero is located right at the low frequency pole in the control-to-output transfer function. As shown in Fig. 12, the bandwidth of the loop gain for the proposed PCCM converter is $17 \mathrm{kHz}$, which is 24 times larger than that of the CCM converter. 

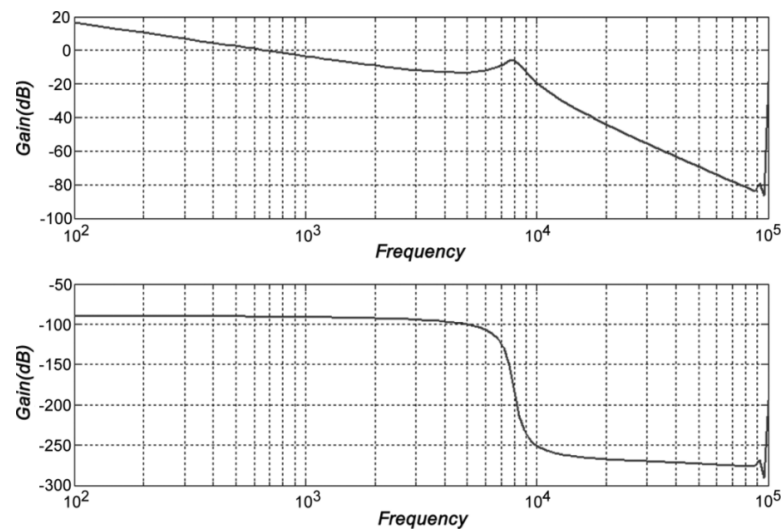

Fig. 11. Loop gain of the CCM converter.
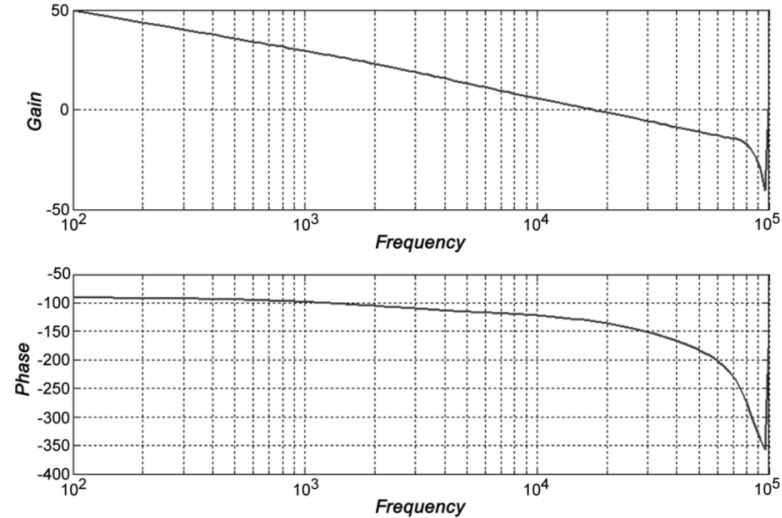

Fig. 12. Loop gain of the PCCM converter.

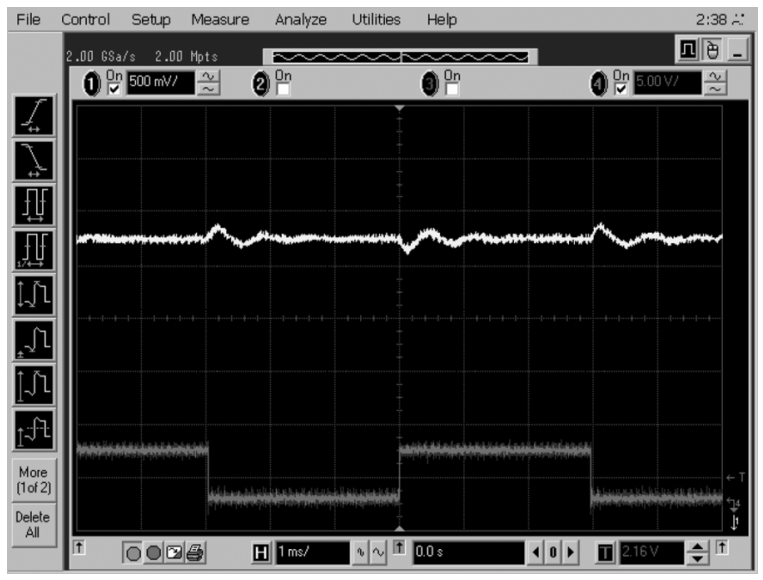

Fig. 13. Load transient performance of the CCM converter.

Load transient measurements were then performed. For each of the converters, we periodically switched the load between 3 and $6 \mathrm{~W}$. Due to different response times, the load of the PCCM converter was switched much quicker than that of the CCM converter. Figs. 13 and 14 show the measured results of the CCM and the PCCM converter, respectively. In each figure, the upper waveform shows the output voltage of the converter, while the lower one shows the load current. In Fig. 13, for the CCM converter, the measured transient response to the described load change is $1.4 \mathrm{~ms}$, with a peak-to-peak voltage variation of 310

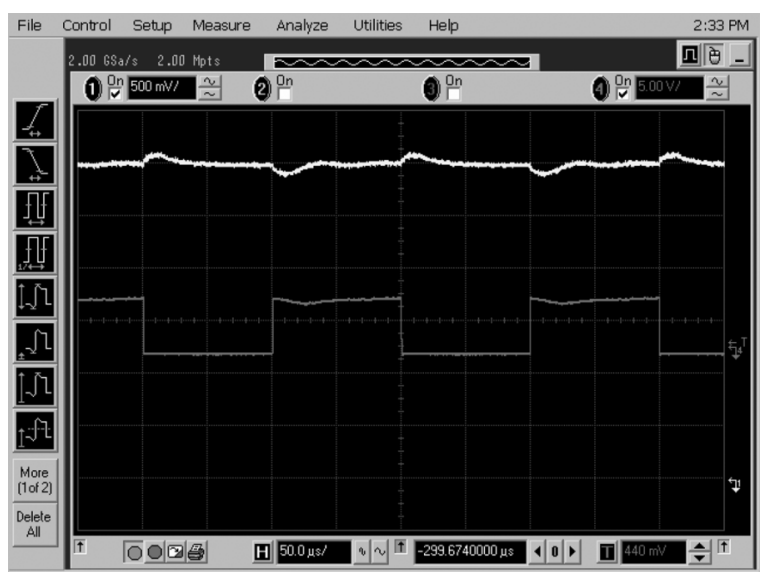

Fig. 14. Load transient performance of the PCCM converter.

$\mathrm{mV}$. In Fig. 14, for the PCCM converter, the measured transient response to a much faster load change is only $25 \mu \mathrm{s}$, with a peak-to-peak voltage variation of $185 \mathrm{mV}$.

\section{CONCLUSION}

A pseudo CCM buck converter with freewheel switching control is proposed in this brief. The new converter inherits the advantages of both CCM and DCM converters: it can handle large current stress while maintaining low current ripple and switching noise. The control-to-output part of the converter only introduces one single low-frequency pole. Pole-zero compensation can thus be used to achieve a faster transient performance. Simulation and experimental results successfully verified the merits of the proposed design.

\section{REFERENCES}

[1] International Technology Roadmap for Semiconductors, 2003 Edition, 2003 [Online]. Available: http://www.public.itrs.net/

[2] M. T. Zhang et al., "Design consign considerations for low-voltage on-board DC/DC modules for next generations of data processing circuits," IEEE Trans. Power Electron., vol. 11, no. 3, pp. 328-337, Mar. 1996.

[3] R. Erickson and D. Maksimovic, Fundamentals of Power Electronics, 2nd ed. Norwell, MA: Kluwer, 2000.

[4] W.-H. Ki, "Signal flow graph in loop gain analysis of dc-dc PWM CCM siwtching converters," IEEE Trans. Circuits Syst. I, Fundam. Theory Appl., no. 6, pp. 644-654, Jun. 1998.

[5] C. Lee and P. Mok, "A monolithic current-mode CMOS dc-dc converter with on-chip current sensing technique," IEEE J.Solid-State Circuits, vol. 39, no. 1, pp. 3-14, Jan. 2004.

[6] W.-H. Ki, "Analysis of subharmonic oscillation of fixed-frequency current-programming switch mode power converters," IEEE Trans. Circuits Syst. I, Fundam. Theory Appl., vol. 45, no. 1, pp. 104-108, Jan. 1998.

[7] V. Tam, "Loop gain simulation and measurement of PWM switching Converters," M.Phil thesis, HKUST, Hong Kong, 1999.

[8] J. Sun et al., "Modeling of PWM converters in discontinous-conduction mode-A reexamination," in Proc. IEEE Power Electron. Specialists Conf., 1998, vol. 1, pp. 615-622.

[9] D. Ma et al., "Single-inductor dual-output CMOS switching converters in discontinuous-conduction mode with time-multiplexing control," IEEE J.Solid-State Circuits, vol. 38, no. 1, pp. 89-100, Jan. 2003.

[10] D. Ma, W.-H. Ki, and C. Y. Tsui, "A pseudo-CCM/DCM SIMO switching converter with freewheel switching," IEEE J. Solid-State Circuits, vol. 38, no. 6, pp. 1007-1014, Jun. 2003.

[11] D. Ma and C. Zhang, "Thermal compensation method for CMOS digital integrated circuits using temperature-adaptive dc-dc converter," IEEE Trans. Circuits Syst. II, Exp. Briefs, vol. 53, no. 11, pp. 1284-1288, Nov. 2006. 